\title{
Maritimes Health Libraries Association (MHLA)
}

It has been a busy time of presentations and movement among members of the health library community in the Maritimes.

In September, Patrick Ellis was chosen to receive the 2012 Outstanding Alumni Award from Dalhousie's School of Information Management. Patrick's well-deserved award was presented 4 October 2012 in Halifax.

Tim Ruggles, long time MHLA member and librarian at Dalhousie's Kellogg Health Sciences Library, retired this past spring after being with the organization for 26 years. Tim was the long time webmaster for MHLA. Kathleen Gadd has graciously assumed those duties. Verona Leslie, Library Tech with Capital District Health Authority, also retired this spring after 34(!) years. Verona was a former president of NSHLA (a predecessor to MHLA). We at MHLA wish both Tim and Verona very happy retirements (and we will try to curb our jealousy!).

The Atlantic Provinces Library Association Conference took place in May in Wolfville, Nova Scotia. Several MHLA members presented posters and presentations on a range of topics including rapid review search models, promoting membership participation in an association, health information needs of the public, embedded librarianship, and health policy language. Abstracts are available on the APLA 2012 Conference website at http:// apla2012.sched.org/.

Jackie MacDonald also presented the CE session Workplace Bullying vs. Position Accountability: the Boundaries of Acceptable Behavior at the 2012 CHLA/ABSC conference in Hamilton.

Lastly, MHLA is looking to make stronger connections to the MLIS and LIT programs in its region. A recent presentation on Associations Day in early September at the Dalhousie School of Information Management garnered 13 new student memberships! We are thrilled and hope to continue to build relationships with the student community.

\section{Michelle Helliwell, MLIS}

President, MHLA 2012-2014

Library \& Knowledge Management Services

Shared Services (Dalhousie School of Nursing - Yarmouth Site, Annapolis Valley Health, South Shore Health,

South West Health)

23 Earnscliffe Ave. Wolfville, NS B4P 1 X4

E-mail: mhelliwell@avdha.nshealth.ca

\section{Québec ASTED-Santé et Services Sociaux}

As part of the 2012 Conference of the Library and Information Community of Quebec (Congrès des milieux documentaires du Québec (CMD) 2012) "Creating, Sharing, and Transferring Know-How," Asted-Health and Social Services (Santé et services sociaux) held a Colloquium entitled "La communication scientifique : l'expertise des spécialistes de l'information" (Scientific Communication: Information Specialist Expertise). For this day-long Colloquium, more than 12 lecturers were on the agenda. In the morning, 61 attendees, representing a cross-section of the entire membership of ASTED-Health and Social Services, had the opportunity to learn about a library collaboration with a hospital-based technology assessment unit and a mental health nurses' Journal Club (designed and driven by nurses). These presentations were followed by the Annual General Meeting of the Chapter, during which an invitation to attend the Montreal ABSC/ CHLA 2014 Conference was once again extended. In the afternoon, a bio-informatics curriculum-based teaching experience was presented, followed by a presentation on how to elaborate an institutional communications guide and a talk on an implementation of Koha (inLibro), an open source integrated library system (ILS). A "Lightning talks" workshop concluded the day. Lecturers answered questions in both French and English.

\author{
Monique St-Jean, B.Sc., M.Bibl., MBA \\ Directrice \\ Bibliothèques des sciences de la santé \\ Université de Montréal \\ E-mail: monique.st-jean@umontreal.ca
}

